22. Воробьев В. В., Дронов В. В., Хруслов Г. В. Москва... Россия... Речь и образы: Корректировочный курс по русскому языку и культуре. М. : Русский язык. Курсы, 2002. 295 с.

23. Голева С. А. Лингвокультурологический и ономастический компоненты концепта «город» в русском и английском языках : дис. ... канд. филол. наук. Омск, 2006. 198 с.

24. Даль В. И. Толковый словарь живого великорусского языка : в 4 т. М. : Русский язык, 1998. Т. 1. 779 с.

25. Кузнецов С. А. Большой толковый словарь русского языка. СПб. : Норинт, 2001. 1536 с. URL: https://gufo.me/dict/ kuznetsov (дата обращения: 02.10.2019).

26. Вострякова Н. А. Особенности «Дороги в Россию» (методический анализ первой части учебного комплекса) (Рец. на кн. : Дорога в Россию: учеб. Русского языка (эле- ментарный уровень) / В. Е. Антонова [и др. ]. 2-е изд., испр. М. : ЦМО МГУ им. М. В. Ломоносова ; СПб. : Златоуст, 2003. 344 с. // Вестн. Воронеж. гос. ун-та. Сер.: Лингвистика и межкультурная коммуникация. 2013. № 1. С. 227-230. URL: https://cyberleninka.ru/article/n/osobennosti-dorogi-v-rossiyumetodicheskiy-analiz-pervoy-chasti-uchebnogo-kompleksa-retsna-kn-doroga-v-rossiyu-ucheb-russkogo-yazyka (дата обращения: 24.11.2020).

27. Беляева Г. В., Нахабина М. М. Я пишу по-русски: элементарный уровень : [пособие для иностранных учащихся : 16+]. 2-е изд., испр. СПб. : Златоуст, 2017. 288 с.

(C) Глушкова Т. С., 2020
УДК 378.14

Науч. спец. 13.00 .08

DOI: 10.36809/2309-9380-2020-29-108-112
И. М. Колышкина, Н. П. Кремнева, А. В. Родионова I. M. Kolyshkina, N. P. Kremneva, A. V. Rodionova

\section{DISTANCE LEARNING: HISTORICAL AND PRAGMATIC ASPECTS (FROM THE EXPERIENCE OF WORKING WITH FOREIGN STUDENTS AT THE PRE-UNIVERSITY STAGE OF TRAINING)}

The article is devoted to the history of distance learning abroad and in Russia, as well as to the practical description of the process of organizing the study of Russian as a foreign language in the remote form of classes. The authors consider various options for organizing the educational process in an online format, identify the main difficulties that arise in the process of distance learning, and show solutions using various online resources: the social network VKontakte, the Skype application, and Google tools. Special attention is paid to the positive and negative aspects associated with the use of this form of training when organizing work with foreign students at the pre-University stage of training.

Keywords: Russian as a foreign language, distance education, online learning, social network VKontakte, Google tools, Skype.
В настоящее время на фоне обрушившейся на мир пандемии особенно актуальным стал вопрос о перспективности дистанционного обучения в рамках как школьного, так и вузовского образования. Высокий уровень развития технологий предоставляет большие возможности для реализации данного направления. Вспомним первые шаги на пути рождения данной формы обучения.

Термин «дистанционное», или «корреспондентское», обучение был введен в конце XVIII в. в Великобритании Исааком Питманом [1]. Его практическое использование предполагало, что студенты получали материал и сда- вали экзамен, используя почтовую связь. У этой модели организации учебного процесса был один большой минус - затратность по времени. Однако идея И. Питмана, рассылавшего свои уроки в формате писем, привлекла внимание научного сообщества, так как ее основной целью было дать возможность получения образования всем желающим, независимо от национальности, религии и места жительства.

Во второй половине XIX в. «корреспондентское» обучение получило весьма широкое распространение в американской системе образования. Так, Анна Тикнор организо- 
вала курсы для женщин с использованием почтовой связи. В 1874 г. В. Р. Харпером была разработана целая авторская программа удаленного обучения, а в 1892 г. в Чикаго открылся первый факультет, осуществляющий образовательный процесс дистанционно [2].

Следует отметить, что на тот момент четкого разграничения понятий заочного и дистанционного обучения не было, зачастую они подменялись одно другим. Так, в 1856 г. в Берлине был основан институт заочной формы, образовательный процесс в котором также осуществлялся посредством почтовых отправлений. Впоследствии удаленное обучение стало популярным в университетах США и Европы, причем коснулось оно не только высшего образования, но и начальной школы.

Новые возможности для дистанционного обучения были открыты с появлением радио. Многие университеты успешно использовали радиовещание, разработав целые курсы. Кроме того, в 1934 г. в государственном университете Айовы впервые был создан образовательный канал, деятельность которого остается актуальной до сих пор. Далее, развитию удаленного обучения способствовало телевидение, теперь уже посредством разработки телевизионных курсов, учебных фильмов, которые широко использовались как в американских, так и в европейских университетах [3].

С 1960-х гг. эфффективность и перспективность дистанционного обучения получили мировое признание и поддержку ЮНЕСКО, новая форма стала успешно развиваться в ногу С научно-техническим прогрессом. В 1969 г. в Великобритании был основан первый в мире университет дистанционного образования, где сегодня осваивают различные специальности более 200000 слушателей [4].

Развитию дистанционного обучения способствовало появление Интернета. Внедрение новых информационных технологий позволило значительно расширить целевую аудиторию обучающихся, предоставив огромные возможности как для преподавательской, так и для студенческой деятельности. Всемирно развитая сеть сделала дистанционное обучение доступным и доминирующим, особенно для людей, совмещающих работу с учебой. Были разработаны стандартные платформы для онлайн-курсов, предполагающие отправление учебных материалов, контрольных работ и других видов заданий через Интернет. Значительно возросло число университетов, практикующих удаленное обучение.Таким образом, новая форма получила широкое распространение во многих учебных заведениях развитых стран.

Абсолютно закономерным стал тот факт, что данные изменения затронули и российскую систему образования. Согласно «Концепции создания и развития дистанционного образования в РФ» от 31 мая 1995 г. под дистанционным образованием понимается «комплекс образовательных услуг, предоставляемых широким слоям населения в стране и за рубежом с помощью специализированной информационной образовательной среды, базирующейся на средствах обмена учебной информацией на расстоянии (спутниковое телевидение, радио, компьютерная связь и т. п.)» [5]. Минобразования РФ 30 мая 1997 г. издало приказ № 1050
«О проведении эксперимента в области дистанционного образования», принятие которого было направлено на развитие и совершенствование методов дистанционного образования и на повышение образовательного уровня населения [6].

Новый виток развития в этой сфере - начало «нулевых» - связан, прежде всего, с подписанием меморандума ЮНЕСКО, что обеспечило России поддержку и содействие в развитии дистанционного образования. В последующее десятилетие это позволило нашей стране выйти на международный уровень в области разработки образовательных программ и систем для организации обучения в дистанционном формате.

В период с 2012 по 2020 г. был принят ряд документов, регламентирующих процесс внедрения дистанционного обучения в систему российского образования и регулирующих деятельность педагогов-тьюторов [7; 8; 9].

Последние события в мире показали, что сегодня дистанционное образование относительно новое и молодое направление организации учебного процесса для российских школ и вузов.

Как известно, в марте 2020 г. образовательный процесс не только в России, но и во всём мире претерпел кардинальные изменения. Из-за угрозы распространения пандемии коронавируса произошел резкий переход от традиционных аудиторных занятий к дистанционной модели обучения. Новый формат работы с обучающимися продемонстрировал не только широкие возможности и перспективы виртуального образования, но и очевидные проблемы, связанные с организацией образовательного процесса в условиях онлайн-обучения. Благодаря открытию дистанционной формы обучения для иностранных студентов российские вузы получили возможность выйти на международный образовательный рынок, разработав собственные онлайн-ресурсы и сервисы: «Цифровой подготовительный фракультет» РУДН [10], «Образование на русском» Государственного института русского языка им. А. С. Пушкина [11].

Липецкий государственный педагогический университет им. П. П. Семенова-Тян-Шанского оказался в числе учебных заведений, которые сразу перешли на дистанционную форму организации учебного процесса. В условиях оперативного изменения формата работы и взаимодействия с обучающимися у преподавателей кафедры «Русского языка как иностранного» возникли дополнительные трудности, напрямую связанные с особенностями контингента слушателей подготовительного отделения. Несмотря на эти сложности, в университете была налажена четкая система организации учебного процесса для иностранных обучающихся в условиях дистанционного обучения. Остановимся на этом более подробно.

Современная виртуальная образовательная среда предоставляет пользователю различные образовательные платформы и программные ресурсы для реализации дистанционной модели учебного взаимодействия между преподавателем и студентом. К их числу относится социальная сеть «ВКонтакте». Следует пояснить, что в нашем случае такой выбор был обусловлен следующими причинами. В начале обучения среди студентов-иностранцев был 
проведен опрос, целью которого было выяснить, зарегистрированы ли они на каких-либо онлайн-платформах, если да, то, на каких и почему. Результаты опроса показали, что подавляющее большинство респондентов - активные пользователи социальной сети «ВКонтакте». Эти данные стали отправной точкой, позволившей организовать взаимодействие между преподавателями и студентами при переходе на дистанционное обучение.

Онлайн-платформа «ВКонтакте» располагает широким спектром инструментов, которые можно использовать для обучения. Так, например, она позволяет создавать учебные сообщества с разными вариантами доступа: открытые, закрытые и частные. Исходя из этого, каждый преподаватель имеет возможность создать соответствующий контент.

Перед началом обучения в таком фрормате следует провести ряд подготовительных мероприятий: проинформировать студентов о необходимости стать подписчиком нового учебного сообщества, рассказать о правилах организации его работы. Например, обучающиеся должны четко представлять объем дистанционного курса, характер материалов, которые будут размещаться в беседе или на стене группы, для каких целей следует использовать функцию личного сообщения.

В нашем случае весь информационный массив, который размещался на странице сообщества, был разделен следующим образом: стена - хранилище разного рода учебных материалов; общая беседа - импровизированная площадка для обсуждения и актуализации новых теоретических знаний; личные сообщения - место размещения новых и выполненных домашних заданий в формате документа, который в случае необходимости можно прокомментировать.

Например, начиная изучение темы «Родительный падеж. Выражение времени», преподаватель разместил на стене сообщества файл следующего содержания:

Родительный падеж. Выражение времени.

Изучите следующие теоретические сведения. Ответьте на вопросы и выполните задания.

Таблица 1

\begin{tabular}{|c|c|}
\hline $\begin{array}{l}\text { Какое число? } \\
\text { И. п. (1) }\end{array}$ & $\begin{array}{l}\text { Когда? } \\
\text { Р. п. (2) } \\
\end{array}$ \\
\hline $\begin{array}{l}\text { Какое сегодня число? } \\
\text { Сегодня десятое (1) апре- } \\
\text { ля (2). }\end{array}$ & $\begin{array}{l}\text { Когда будет урок? } \\
\text { Урок будет десятого (2) апре- } \\
\text { ля (2). }\end{array}$ \\
\hline $\begin{array}{l}\text { Какое число было вчера? } \\
\text { Вчера было девятое (1) апре- } \\
\text { ля (2). }\end{array}$ & $\begin{array}{l}\text { Когда был урок? } \\
\text { Урок был девятого (2) апре- } \\
\text { ля (2). }\end{array}$ \\
\hline $\begin{array}{l}\text { Какое число будет завтра? } \\
\text { Завтра будет одиннадцатое } \\
\text { (1) апреля (2). }\end{array}$ & $\begin{array}{l}\text { Когда будет урок? } \\
\text { Урок будет одиннадцатого (2) } \\
\text { апреля (2). }\end{array}$ \\
\hline $\begin{array}{l}\text { Дата (И. п. 1) + Месяц (Р. п. 2) } \\
\text { Модель: } 1 \text { + } 2\end{array}$ & \begin{tabular}{|l} 
Дата (Р. п. 2) + Месяц (Р. п. 2) \\
Модель: 2 + 2
\end{tabular} \\
\hline
\end{tabular}

Таблища 2

\begin{tabular}{|l|l|}
\hline $\begin{array}{l}\text { Какое сегодня число? } \\
\text { И. п. (1) }\end{array}$ & $\begin{array}{l}\text { Когда он родился? } \\
\text { Когда это произошло? (Когда } \\
\text { случилось?) } \\
\text { Р. п. (2) }\end{array}$ \\
\hline $\begin{array}{l}\text { Сегодня десятое (1) апреля } \\
\text { (2) две тысячи двадцатого (2) }\end{array}$ & $\begin{array}{l}\text { Он родился десятого (2) апре- } \\
\text { ля (2) две тысячи двадцатого } \\
\text { года. }\end{array}$ \\
(2) года. \\
$\begin{array}{l}\text { Вчера было девятое (1) апре- } \\
\text { ля (2) две тысячи двадцатого } \\
\text { (2) года. }\end{array}$ & Это произошло девятого (2) \\
\hline $\begin{array}{l}\text { Дата (И. п. 1)+ Месяц (Р. п. 2) + }+ \\
\text { Год (Р. п. 2) }\end{array}$ & $\begin{array}{l}\text { Дата (Р. п. 2) + Месяц (Р. п. 2) + } \\
\text { Год (Р. п. 2) } \\
\text { Модель: 1 + 2 + 2 }\end{array}$ \\
\hline
\end{tabular}

1. Какие новые вопросы вы узнали?

2. Прочитайте модели из таблицы 1.

3. Чем они похожи? В чем отличие?

4. Запомните падежи.

5. Составьте по аналогии свои примеры.

6. Прочитайте модели из таблицы 2.

7. Назовите новый показатель времени. Обратите внимание на правила его изменения.

8. Обратите внимание на глаголы.

9. Запомните падежи.

10. Составьте по аналогии свои примеры.

\section{Родиться}

Я, ты, он родился

Я, ты, она родилась

Мы, вы, они родились

Естественно, чтобы изучение теоретических сведений для обучающихся было продуктивным, преподаватель должен контролировать этот процесс. Для этих целей можно воспользоваться общей беседой, которая позволит сделать коммуникацию более конструктивной. Необходимо обязательно проинформировать всех участников группы о времени начала и конца обсуждения соответствующей темы, а также убедиться, что все студенты вышли на связь.

Непосредственное интерактивное общение происходит между обучающимися, которые пытаются представить свое видение вопроса, в силу того, как он был ими понят. Преподавателю отводится роль наблюдателя, фиксирующего вектор движения каждого студента, правильность и точность усвоения каждым участником теоретической базы. Так, при обсуждении представленной выше темы, больше всего вопросов было связано с правилами изменения числительных - показателя года. Анализ беседы позволил преподавателю внести необходимые корректировки при подготовке соответствующего тематического вебинара.

Онлайн-платсрорма «ВКонтакте» позволяет вести прямую трансляцию вебинаров непосредственно со страницы сообщества. Информация о времени проведения очередного мероприятия размещается на стене сообщества заранее, приглашение на вебинар участники получают за несколько минут до его начала. Таким образом, у преподавателя 
появляется дополнительная возможность актуализировать теоретический материал с учетом возникших трудностей и индивидуальных ошибок студентов.

Наряду с положительными моментами - простота использования, доступность, популярность - в ходе организации работы с обучающимися в данной социальной сети были выявлены следующие минусы:

1) отсутствие возможности отслеживать включенность слушателей в образовательный процесс (невозможно проконтролировать, заходил ли студент в группу, с какими материалами конкретно он знакомился и знакомился ли вообще);

2) сложности, возникающие при проверке домашнего задания, различных контрольных и тестовых материалов (работа проверяется вручную, отсюда длительность и растянутость получения результатов во времени);

3) невозможность быстро и оперативно информировать обучающихся о результатах выполнения ими заданий.

Именно поэтому в дальнейшем данный онлайн-сервис использовался преподавателями для активного обмена информацией как в синхронном, так и в асинхронном режиме взаимодействия, а сами занятия проводились с помощью «Скайпа».

Приложение «Скайп» очень удобно тем, что в нем есть функция «Демонстрация экрана», позволяющая любому из участников видеозвонка показывать остальным изображение монитора своего компьютера. Это дает преподавателю возможность демонстрировать презентации, различные фото- и видеоматериалы. В отличие от онлайн-платформы «ВКонтакте» при работе в «Скайпе» взаимодействие между преподавателем и студентами ведется в синхронном формате, что обеспечивает мобильность и оперативность при обмене информацией и выполнении студентами различных заданий, обучающиеся могут активно взаимодействовать друг с другом, а преподаватель контролирует ход занятия.

При организации дистанционного обучения, в процессе подготовки и проведения занятий преподавателями кафедры русского языка как иностранного активно использовались гугл-инструменты. «GoogleSlides» - это ведущее приложение «Google» для презентаций, которое находится в браузере как часть https://docs.google.com/ («GoogleDocs»). Важно отметить, что оно абсолютно бесплатное, единственное требование для использования - это наличие учетной записи Google. Его основные плюсы:

1) контроль темпа выполнения заданий каждым студентом;

2) приобретение иностранцем навыка пользования русской клавиатурой;

3) использование различных вариантов проверки (перекрестная, самопроверка по ключу);

4) использование упражнений разных видов, разной степени сложности;

5) возможность быстро и легко «освежить» коммуникативные упражнения и ярко представить грамматический материал;

6) наличие функции совместной работы.

При создании презентаций для иностранных студентов необходимо использовать минимум текста, максимум таб- лиц, схем и картинок. Основной принцип при работе с этим приложением - презентация не должна заменять преподавателя, она должна помочь систематизировать материал и дать возможность заинтересовать обучающихся.

Так, например, при изучении глаголов движения для каждого студента преподавателем был создан «GoogleSlide» определенного цвета, на котором они в режиме реального времени проведения занятия выполняли следующее грамматическое задание: вставьте в текст верные глаголы движения. Аналогичные задания были разработаны и опробированы при закреплении употребления слова «который» в разных падежах. Студентам предлагалось выполнить следующее задание: напишите слово «который» в правильном падеже.

Особо следует отметить, что в условиях дистанционного обучения повышается роль и значение домашнего задания. Благодаря использованию «GoogleForms» мы немного «облегчили» себе жизнь, так как домашние задания в форме небольших и разнообразных тестов проверялись автоматически, а результаты студентов приходили на почту преподавателям. Кроме того, в «GoogleForms» можно выставить время для выполнения тестов, данную функцию можно использовать при проведении не только самостоятельных, контрольных работ, но и на зачетах или экзаменах.

Подводя итог вышесказанному, следует подчеркнуть, что дистанционная форма обучения имеет свои плюсы и минусы.

На наш взгляд, к ее достоинствам следует отнести:

1) интерактивность;

2) быстрое и эфффективное взаимодействие между студентом и преподавателем;

3) использование современных технологий в учебном процессе;

4) развитие навыков самостоятельной работы;

5) спокойная обстановка;

6) создание благоприятных условий для творческого самовыражения студента в процессе усвоения знаний.

Среди отрицательных моментов мы выделили:

1) необходимость постоянного доступа к Интернету;

2) отсутствие самодисциплины и мотивации у студенTOB;

3) проблема организации контроля учебного процесса;

4) сложности, связанные с удержанием внимания и включением студентов в процесс обучения;

5) дефицит личного контакта с преподавателем и сокурсниками.

Последние события, произошедшие в мире, показали, насколько дистанционное обучение актуально и востребовано, несмотря на все недостатки. В новом тысячелетии в результате стремительного проникновения информационных технологий в разные сферы жизни дистанционная форма обучения будет всё активнее и активнее заявлять o ceбе.

1. Miller G. History of Distance Learning. Education Guidance. American Inter Continental University Online. 2014. November 10. URL: http://www.worldwidelearn.com/educa- 
tion-articles/history-of-distance-learning.html (дата обращения: 29.08.2020).

2. Пьянников М. М. К вопросу об истории дистанционного образования // Учен. зап. ЗабГУ. Серия: Педагогические науки. 2011. № 5. С. 112-123.

3. Девтерова 3. Р. Основные этапы развития и современное состояние дистанционного обучения в России // Гуманизация образования. 2010. № 3. URL: https://cyberleninka. ru/article/n/osnovnye-etapy-razvitiya-i-sovremennoe-sostoyaniedistantsionnogo-obucheniya-v-rossii (дата обращения: 29.08.2020).

4. Чубарова О. И. Дистанционное обучение как приоритетная форма современной технологии обучения в системе высшего образования // Изв. АлтГУ. 2002. № 8. C. 153-156. URL: https://cyberleninka.ru/article/n/distantsionnoeobuchenie-kak-prioritetnaya-forma-sovremennoy-tehnologiiobucheniya-v-sisteme-vysshego-obrazovaniya (дата обращения: 29.08.2020).

5. Концепция создания и развития дистанционного образования в России // Pandia : [сайт]. URL: https://pandia.ru/ text/78/302/22561.php (дата обращения: 29.08.2020).

6. Приказ Минобрнауки России от 30 мая 1997 года № 1050 «О проведении эксперимента в области дистанционного образования» // КонсультантПлюс : [сайт]. URL: http://www.consultant.ru/cons/cgi/online.cgi?req=doc\&base=E $X P \& n=274341 \& d s t=100001 \# 04890233133389954$ (дата обращения: 29.08.2020).

7. Федеральный закон «Об образовании в Российской Федерации» от 29 декабря 2012 г. № 273-Ф3 // Консультант-

УДК 378.147

Науч. спец. 13.00 .08

DOI: 10.36809/2309-9380-2020-29-112-116

\section{СТРАТЕГИЯ ПРАКТИЧЕСКОЙ ПОДГОТОВКИ СТУДЕНТОВ В ОБРАЗОВАТЕЛЬНОМ ПРОЦЕССЕ ПЕДАГОГИЧЕСКОГО ВУЗА}

В статье предложена стратегия практической подготовки студентов педагогического вуза, цель которой - обоснование ключевых приоритетов и направлений ее развития. Авторами определены задачи практической подготовки, заключающиеся в обеспечении готовности студентов к решению профессиональных задач в условиях неопределенности, к развитию умения применять знания и опыт в образовательной практике, к формированию способности осуществлять выбор на основе собственной профессиональной позиции.

Ключевые слова: практическая подготовка, высшее образование, основная профессиональная образовательная программа, педагогическое образование.
Плюс : [сайт]. URL: http://www.consultant.ru/documentcons_ doc_LAW_140174 (дата обращения: 29.08.2020).

8. Приказ Минобрнауки России «Об утверждении порядка применения организациями, осуществляющими образовательную деятельность, электронного обучения, дистанционных образовательных технологий при реализации образовательных программ» от 9 января 2014 г. № 2 // Контур.норматив : [сайт]. URL: https://normativ.kontur.ru/doc ument?moduleld=1\&documentld=229050 (дата обращения: 29.08.2020).

9. Приказ Министерства образования и науки РФ «Об утверждении порядка применения организациями, осуществляющими образовательную деятельность, электронного обучения, дистанционных образовательных технологий при реализации образовательных программ» от 23 августа 2017 г. № 816 // Контур.норматив : [сайт]. URL: https:// normativ.kontur.ru/document?moduleld=1\&documentld=300600 (дата обращения: 29.08.2020).

10. Цифровой подготовительный факультет // Российский университет дружбы народов : [сайт]. URL: http://www. rudn.ru/media/news/admission/cifrovoy-podgotovitelnyy-fakultet (дата обращения: 29.08.2020).

11. Образование на русском: проект Государственного ин-та рус. яз. им. А. С. Пушкина : портал. URL: https:// pushkininstitute.ru/about (дата обращения: 29.08.2020).

(C) Колышкина И. М., Кремнева Н. П., Родионова A. B., 2020

Н. С. Макарова, Е. В. Черненко

N. S. Makarova, E. V. Chernenko

\section{THE STRATEGY}

\section{FOR THE PRACTICAL TRAINING OF STUDENTS IN EDUCATIONAL PROCESS OF A PEDAGOGICAL UNIVERSITY}

The article substantiates the strategy of practical training of students of a pedagogical University, the purpose of which is to justify the key priorities of practical training and directions of its development. The authors define the tasks of practical training, which consist in ensuring students' readiness to solve professional problems in conditions of uncertainty, developing the ability to apply knowledge and experience in educational practice, and forming the ability to choose solutions based on their own professional position.

Keywords: practical training, pedagogical education, higher education, main professional educational program.
Нормативными актами Министерства образования и науки РФ от 5 августа 2020 г. вновь актуализирована про- блема практической подготовки обучающихся в образовательных учреждениях высшего образования. Пунктом 24 